\title{
Catalytic combustion of brown coal particulates over ceramometal honeycomb catalyst
}

\section{Abstract}

Catalytic combustion of brown coal particulates over $\mathrm{CuO} / \mathrm{Al}_{2} \mathrm{O}_{3} / \mathrm{FeAlO} /$ FeAl honeycomb ceramometal catalyst in the fluidized bed regime with the sand as a heat transfer material has been studied during 100 hours at $973-1023 \mathrm{~K}$. The catalyst before and after tests has been analyzed. The coal conversion in the presence of cermet catalyst was found to be in the range of $97.8-98.5 \%$ while without catalyst it was lower (91.2-94.6\%). A substantial decrease of $\mathrm{CO}, \mathrm{NOx}$ and $\mathrm{SO}_{2}$ emissions in catalytic combustion was also demonstrated.

Keywords

Catalytic combustion $\bullet$ Coal particulates $\bullet$ Ceramometal catalyst

(C) Versita Sp. z o.o.
Serguei F.Tikhov ${ }^{1,2 *}$ Aleksandr D.Simonov ${ }^{1}$ Nikolai A.Yazykov',

Yurii V. Dubinin', Vadim A.Yakovlev',
Vladislav A.Sadykov ${ }^{1,3}$ Aleksey N.Salanov ${ }^{1}$ Evgenii A.Suprun', Valentin N.Parmon ${ }^{1,3}$
'Boreskov Institute of Catalysis,

Pr. Akademika Lavrentieva 5, 630090 Novosibirsk, Russian Federation

2Sibcermet Ltd., Lavrentieva Str., 5,

Novosibirsk, Russia, 630090

Received 25 February 2013

Accepted 30 April 2013
${ }^{3}$ Novosibirsk State University,

Str. Pirogova 2, 630090,

Novosibirsk, Russian Federation

\section{Introduction}

Catalytic oxidation of various fuels is known to be promising and environmentally benign process of heat generation and can also be widely used for combustion of solid industrial, agricultural and communal wastes too [1-5]. The catalytic oxidation occurs at quite low temperatures (below 1000-1050 K) and is accompanied by the relatively low emission of secondary toxic compounds, while the conventional combustion occurs at high (up to 1500-1900 K) temperatures and leads to the formation of 'thermal' nitrogen oxides, benzpyrenes, etc. The majority of publications on deep catalytic oxidation concerns VOC and gaseous organics, while publications devoted to oxidation of solid particulates are scarce [6].

Earlier, a process of catalytic oxidation of various gaseous, liquid, and solid fuels at moderate $(T \leq 1050 \mathrm{~K})$ temperatures inside the reactor with the fixed bed catalyst and fluidized inert heat transfer material (sand) has been suggested $[7,8]$. Here, sand transfers heat from catalysts (porous ceramic systems) to a heat exchanger, thus increasing the heat transfer coefficient. The fixed catalyst bed is comprised of conventional catalytically active oxide ceramics shaped as rings and situated between special grids which prevent formation of bubbles. As a result, degree of the fuels combustion was increased while $\mathrm{CO}$, nitrogen oxides and other toxic compounds emission was decreased. However, suggested process design suffers from the loss of catalyst (up to $0.3-0.5 \%$ per day) due to a low attrition resistance of ceramic catalysts. Abrasion of conventional CuCrAlO catalysts produces a powder containing poisonous $\mathrm{Cr}(\mathrm{VI})$ [9]. The metal-based honeycomb catalyst appears to be not applicable here because its active component is concentrated in the external surface layer [10] and, thus, is removed by the abrasive action of fluidized sand. Similarly, traditional catalysts could not be used for combustion of solid wastes containing a lot of mineral non-combustible admixtures.

For these applications we have developed a novel composite ceramometal (cermet) catalyst with enhanced attrition resistance. This cermet consists of the macroporous oxide matrix $\left(\mathrm{MeO}_{x}\right.$; $\mathrm{Me}=\mathrm{Fe}, \mathrm{Cu}, \mathrm{Al})$ with randomly distributed metal particles (Fe, FeAl ${ }_{x}$ ). Contrary to conventional honeycomb structures with the washcoated active component, the active component is also randomly distributed in the cermet catalyst body. So, activity of this catalyst is not diminished significantly after removing its surface layer. Macropores (size up to few tens of microns) provide a low diffusion resistance inside catalysts preventing, however, contact of sand particles with the active component situated in these pores. This paper presents results of pilot tests of new ceramic honeycomb catalysts in the process of the brown coal combustion in the fluidized bed of sand. Evolution of the catalyst properties after testing is also discussed.

\section{Experimental Procedures}

\subsection{Catalyst preparation}

Preparation of cermet support includes mechanical alloying of Fe-Al powdered blend followed by its mixing with alumina 
(prepared from product of gibbsite thermochemical activation (TCA) [11]), loading into a special die and hydrothermal treatment (HTT) of the blend which cements it into a monolith. Then the product of $\mathrm{HTT}$ was dried and calcined at $1173 \mathrm{~K}$. Main details of cermet preparation are described elsewhere [12]. These cermets can be shaped as rings, plates and honeycombs, the latter (Figure 1) posessing a large share of free space (large channels). Active component is supported by conventional impregnation of monolithic substrate with $\mathrm{Cu}$ nitrate solution followed by drying and calcination under air at $973 \mathrm{~K}$.

\subsection{Catalyst characterization}

The crushing (compressing) strength of catalyst was determined by crushing its pellets (diameter $\sim 10 \mathrm{~mm}$, height $\sim 3 \mathrm{~mm}$ ) between two parallel plates in static conditions using a PK-2-1 instrument. The strength value was estimated as a ratio of the loaded stress at the crushing point to the section area of the pellet. The attrition resistance was estimated by weighting the honeycombs before and after the testing.

Details of the catalyst microstructure were studied with a scanning electron microscope JEOL JSM-6460LV equipped with an EDX-INCA Energy-350 (Oxford Inst.) spectrometer. For SEM studies, a cermet sample was cut and polished to obtain a flat cross-section. The accelerating voltage used for registration of SEM images and EDX analysis of surface segments was equal to $20 \mathrm{keV}$. The values of the atomic concentrations obtained after standard computer processing included decimal values, though the actual errors, caused by difference in the dimensions of the analysis regions for the light and heavy elements, may be as high as few rel.\%. The X-ray color compositional mapping has been used as a critical tool for combining information from X-Ray maps of different elements $[13,14]$.
The X-ray diffraction (XRD) patterns were registered using a HZG-4C diffractometer (CuKa radiation, step $0.05^{\circ}$, accumulation time $3 \mathrm{sec}$, voltage $40 \mathrm{kV}$, current $35 \mathrm{~mA}$ ).

The mesopore size distribution and BET surface area $\left(\mathrm{S}_{\mathrm{BET}}\right)$ were derived from adsorption isotherms measured at $77 \mathrm{~K}$ using a Micromeritics ASAP-2400 instrument. The volume of mesopores $\left(\mathrm{V}_{\text {meso }}\right)$ and their average diameter (D) were estimated from the desorption branch of isotherms using relation $\mathrm{D}=4 \mathrm{~V}_{\text {meso }} / \mathrm{S}$. The total pore volume of monoliths was calculated from the apparent and real densities of granules.

\subsection{Catalytic Activity Measurements}

Catalytic pilot tests have been carried out in a flow system with the fluidized bed of brown coal particulates $(\leq 5 \mathrm{~mm})$ mixed with quartz sand (particle size $1-2 \mathrm{~mm}$ ) in the autothermal regime

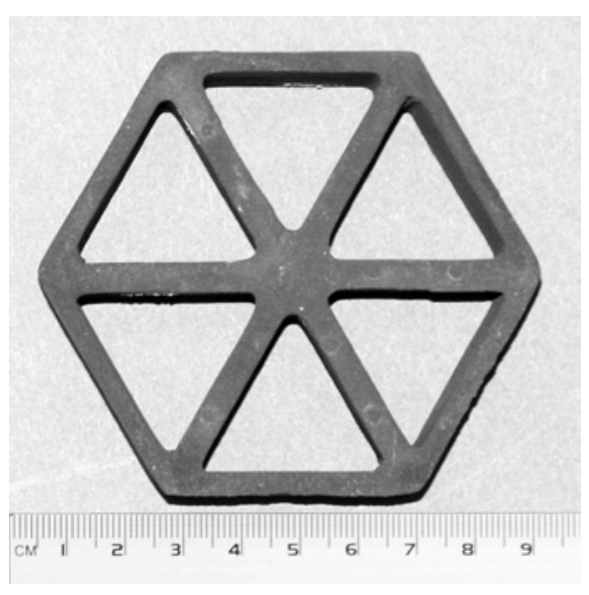

Figure 1. Cross-section of honeycomb cermet catalyst with large channels.

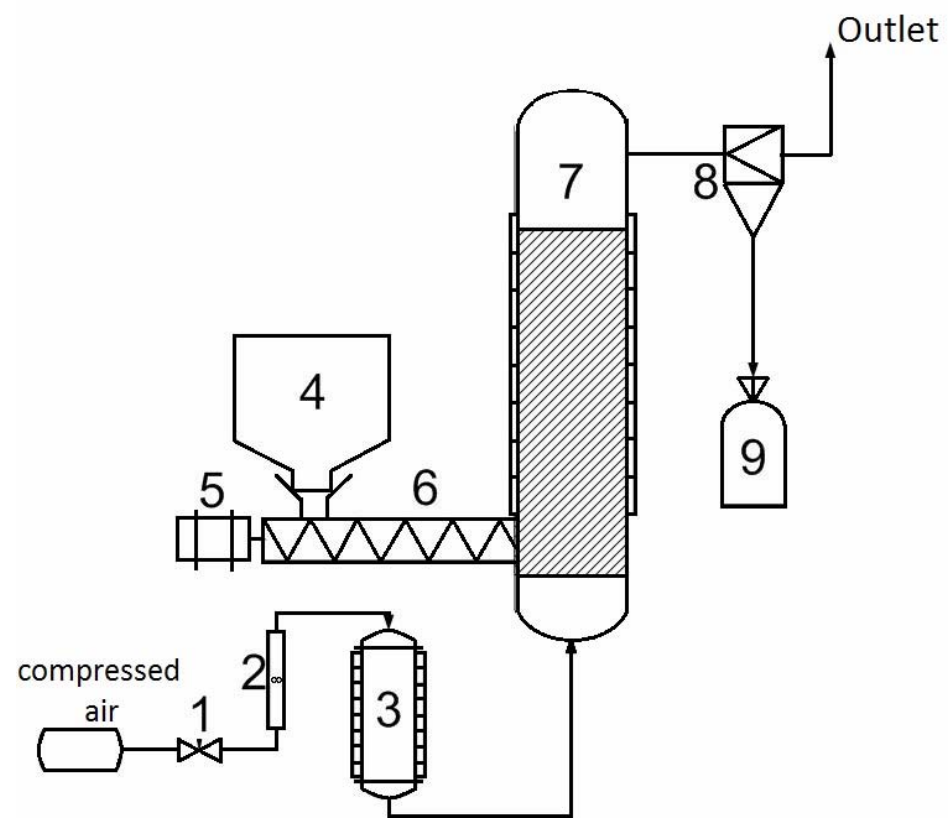

Figure 2. A general scheme of the test installation for coal combustion. 1 - valve; 2 - rotameter; 3 - electric heating unit; 4 - bunker for solid fuel; 5 electromotor; 6 - screw feeder; 7 - a fluidized bed reactor with the electric heater; 8 - cyclone; 9 - bunker for ash. 
( $T=973-1023 \mathrm{~K}$ ) during $100 \mathrm{~h}$. A general scheme of the test installation is presented in Figure 2.

The internal diameter of the stainless steel reactor was $75 \mathrm{~mm}$. The catalyst package with a height of $810 \mathrm{~mm}$ consisted of 14 honeycombs separated by stainless steel rings (Figure 3). The total mass of the catalytic package was $2.1 \mathrm{~kg}$, its volume portion inside the reactor was $24 \%$. Sand loading was $3.5 \mathrm{~L}$. So, the total height of the fluidized bed of sand containing within the catalyst package was $1000 \mathrm{~mm}$.

For comparison, the brown coal oxidation in the fluidized bed of either commercial catalyst IC-12-70 (CuCrAIO [15], spherical particles of $1.5-2.0 \mathrm{~mm}$ in diameter, loading $4.0 \mathrm{~L} / 4.0 \mathrm{~kg}$ ) or sand (particles diameter 1.0-2.0 mm , loading $4.0 \mathrm{~L} / 5.9 \mathrm{~kg}$ ) was carried out. To prevent gas bubbles formation in experiments with coal combustion using a spherical catalyst, stainless steel regulating grids filling ca. 10 vol.\% of reactor were used. These grids were replaced by cermet honeycombs in experiments with structured catalysts.

A typical Kansk-Achinsk coal organic matter composition (weight \%) is $\mathrm{C}-71.5 ; \mathrm{H}-5.0 ; \mathrm{N}-1.0 ; \mathrm{O}-22.1$; $\mathrm{S}-0.4$; ash content in the dried brown coal is $10.1 \%$. The coal consumption is $0.68 \mathrm{~kg} / \mathrm{h}$; air flow $-10 \mathrm{~m}^{3}(\mathrm{STP}) / \mathrm{h}$, the air excess coefficient $(\alpha)$ - 2.65. The brown coal organic matter burn off (b, \%) was estimated taking into account the weight of solid residues remaining after the combustion and the full ash content in the initial coal:

$$
b=10^{4}\left(A_{c}-A_{0}\right) / A_{c}\left(100-A_{0}\right),
$$

$A_{c}$ - ash content in solid residue, \%; $A_{0}$ - ash content in dried initial coal, \%.

The gas phase content $\left(\mathrm{CO}, \mathrm{NO}, \mathrm{NO}_{2}, \mathrm{SO}_{2}, \mathrm{CO}_{2}, \mathrm{CH}_{\mathrm{x}}\right)$ was analyzed using a Chromos $\mathrm{GH} 1000$ gas chromatograph (OOO Chromos, Russia) equipped with a catarometer and a Polar gas analyzer (OOO "Promecopribor", Russia) with electrochemical and IR absorbance gas sensors.

\section{Results and Discussion}

\subsection{Properties of cermet support and catalyst before testing}

The microstructure of cermet support $\mathrm{Al}_{2} \mathrm{O}_{3} / \mathrm{FeAlO} / \mathrm{FeAl}$ as revealed by EDX mapping is presented in Figure 4. One can observe large alumina globules (red) up to few hundred microns in size randomly distributed in the foam-like FeAlO/FeAl cermet matrix (green/salad). Distribution of oxygen in cermet is more uniform because both $\mathrm{FeAlO}$ and $\mathrm{Al}_{2} \mathrm{O}_{3}$ oxides contain it (Figure $4 d$ ). Fe-Al metal inclusions in the cermet matrix with a low oxygen content are seen as salad spots in Figure $4 \mathrm{c}$ and black spots in Figure 4d. Hence, in contrast to catalysts based on monolithic honeycomb substrates [2,3,6], all components including Fe and $\mathrm{Al}$ oxides and metals are uniformly distributed in the bulk of cermet matrix. The FeAlO oxide matrix is reinforced by metal inclusions making cermet mechanically strong. For example, the compressive strength of cermets $(8.6 \mathrm{MPa})$ is higher than that of conventional porous $\mathrm{Cu}-\mathrm{Cr}-\mathrm{O}$ deep oxidation catalyst (1.7-2.3 MPa) prepared by self- propagating high temperature synthesis (SHS) being comparable with other SHS supports with a low specific surface area [16].

According to XRD data, the initial (as prepared) $\mathrm{CuO} / \mathrm{Al}_{2} \mathrm{O}_{3} /$ $\mathrm{FeAlO} / \mathrm{FeAl}$ cermet catalyst consists of metal ( $\mathrm{Fe}, \mathrm{Fe}_{3} \mathrm{Al}$ ) and oxide $\left(\gamma, \delta-\mathrm{Al}_{2} \mathrm{O}_{3}, \alpha-\mathrm{Fe}_{2} \mathrm{O}_{3}, \mathrm{CuO}\right)$ phases (Figure 5).

Along with broad peaks corresponding to $\gamma$ - and $\delta-\mathrm{Al}_{2} \mathrm{O}_{3}$ phases, reflections corresponding to $\alpha-\mathrm{Al}_{2} \mathrm{O}_{3}$ admixture are observed as well. The latter is probably formed after partial oxidation of metal Al remaining after mechanical alloying and HTT at high temperature in air. As judged by the intensity of reflections of initial catalyst and alumina calcined at $900{ }^{\circ} \mathrm{C}$ (Figure 5), the content of $\gamma$ - and $\delta-\mathrm{Al}_{2} \mathrm{O}_{3}$ is small, thus implying

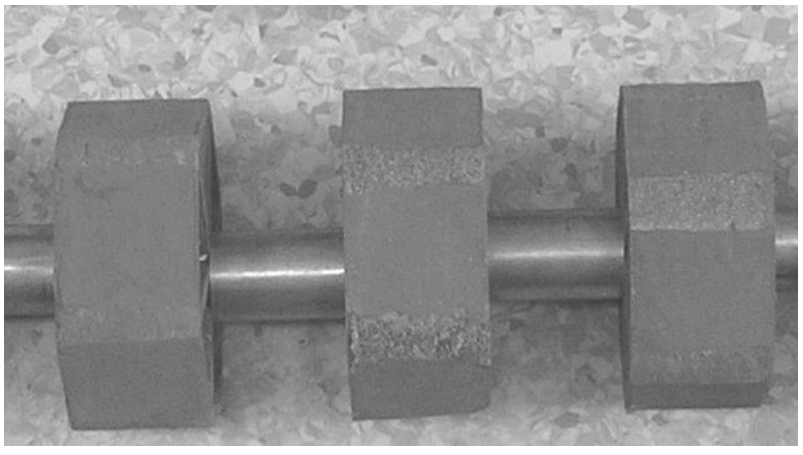

Figure 3. General view of cermet honeycombs separated by stainless steel rings before loading into the reactor.
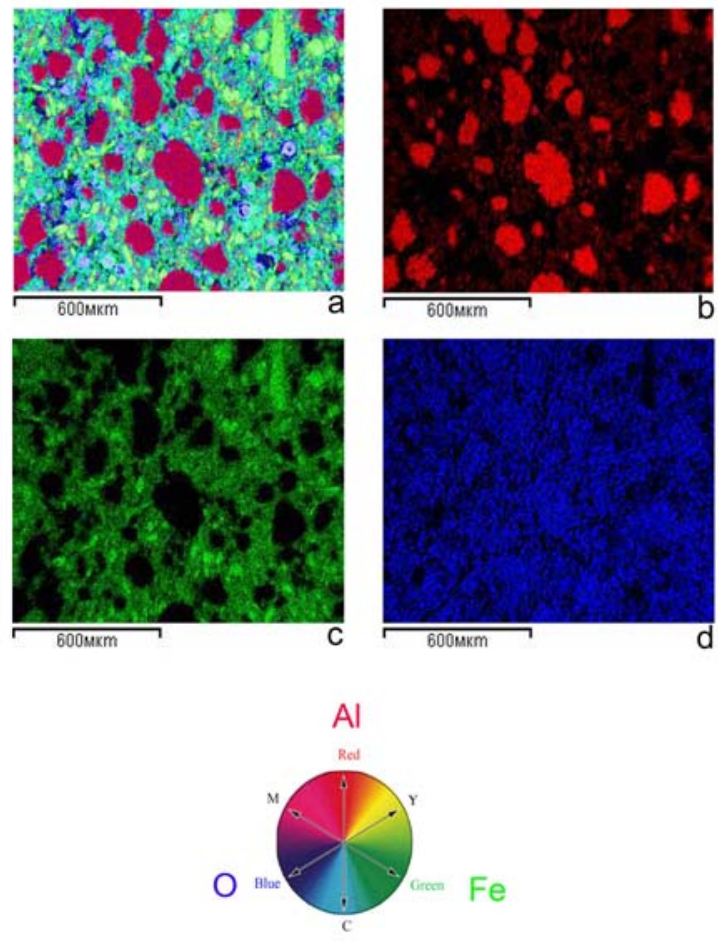

Figure 4. Distribution of different components (phases) according to mapping of the polished surface of cermet support $\mathrm{Al}_{2} \mathrm{O}_{3}$ / FeAlO/FeAl: a - general view, $b$ - pure alumina (red), c - FeA/OI/ $\mathrm{FeAl}$ matrix (green and salad), d-oxygen (blue). Blue and violet spots on a) are ultramacropores. 
presence of X-ray amorphous alumina. The low temperature $\gamma-\mathrm{Al}_{2} \mathrm{O}_{3}$ phase remains in cermet most likely due to a short time of the TCA product high temperature treatment during synthesis.

The specific surface area (SSA) of cermet catalyst is $18.7 \mathrm{~m}^{2} / \mathrm{g}$ and lies between that of porous catalysts prepared by the sol-gel method ( $\left.200 \mathrm{~m}^{2} / \mathrm{g}\right)$ [4] and catalysts prepared by the SHS method $\left(\sim 3 \mathrm{~m}^{2} / \mathrm{g}\right)$ [16]. The volume of mesopores is $0.054 \mathrm{~cm}^{3} / \mathrm{g}$ with maxima at the pore diameters ca. 3 and ca. $10 \mathrm{~nm}$ (Figure 6). Because SSA of pure MeAl cermets is significantly lower and mesopores are large in size [17], the porosity can be mainly assigned to alumina -containing regions. At the first glance, the volume of mesopores in cermets is rather small, however, it is necessary to take into account that in comparison to common porous ceramics with the density of $3.0-3.5 \mathrm{~g} / \mathrm{cm}^{3}$, cermet has significantly bigger real density of $4.5-5 \mathrm{~g} / \mathrm{cm}^{3}$. As the result, the apparent density of ceramic catalyst grains is ca. $1.0 \mathrm{~g} / \mathrm{cm}^{3}$, which is significantly smaller than the density of cermet catalyst bed containing honeycombs even with large channels (Figure 1). Hence, the fraction of mesopores per the unit of volume of cermets and porous ceramic catalysts is comparable. This provides sufficient pore volume to impregnate cermets with solutions of catalytically active component and achieve its good dispersion.

It should be noted that the pore volume of cermets estimated from adsorption isotherms is significantly smaller than the total pore volume derived from the values of apparent and true density of the material $\left(0.14 \mathrm{~cm}^{3} / \mathrm{g}\right)$. This phenomenon is not an inherent feature of porous ceramics. One can assume that this is associated with a developed system of ultramacropores up to $100 \mu \mathrm{m}$ in size, which is indeed a specific feature of porous cermets and could not be estimated by conventional adsorption methods. Such ultramacropores are clearly seen in Figure 4a. These ultramacropores provide a high permeability of cermet catalyst. They are formed due to voids between particles of Fe-Al alloy and alumina (typical size 1-100 microns) in blends filling a die. These macropores are only in part filled by products of hydrothermal treatment and subsequent oxidation, which provide cermet consolidation into the monolith. For pelletized or granulated catalysts the fraction of micropores and their sizes are usually much smaller [18].

A qualitative pore size distribution curves for cermets and other types of porous materials are compared in Figure 7. For traditional porous ceramics used as carriers for supported catalysts, micro- and mesopores are known to dominate. For foam materials and porous metals, ultramacropores with the size up to some millimeters are present [19], which allow deposition of active component from colloid suspensions or slurries. The pore structure of cermets is of intermediate type with comparable fractions of micro-, meso- and ultramacropores (Figure 7).

So, obtained cermet catalyst is characterized by a high mechanical strength and developed system of macropores which provide a high diffusion permeability. Simultaneously, there is a developed system of mesopores localized mainly within globules of alumina. It provides a high dispersion of the active

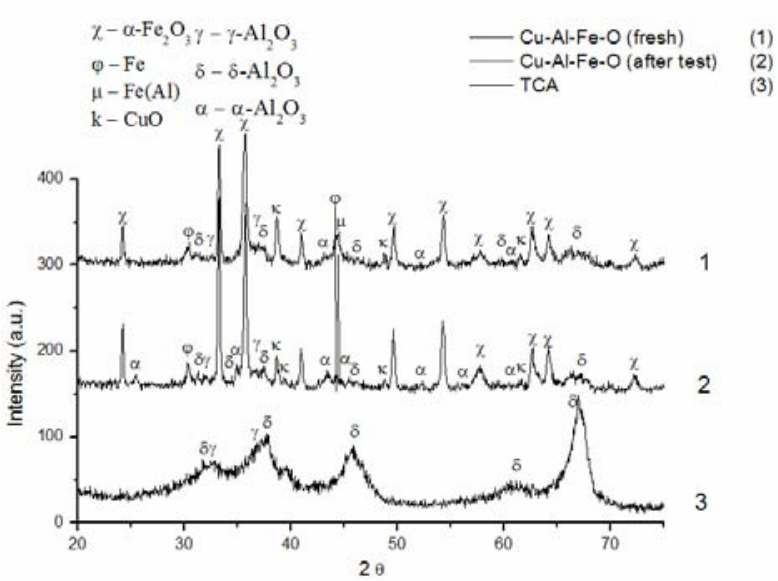

Figure 5. X-Ray diffraction pattern of cermet catalyst $\mathrm{CuO} / \mathrm{Al}_{2} \mathrm{O}_{3} / \mathrm{FeAlO} /$ $\mathrm{FeAl}$ before (1) and after (2) testing, and alumina (product of gibbsite TCA) calcined at $900^{\circ} \mathrm{C}$ (3).

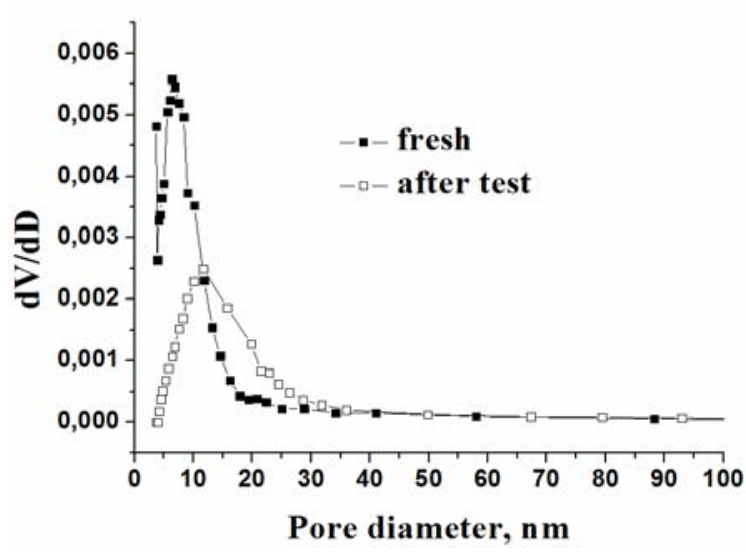

Figure 6. Mesopore size distribution of cermet catalyst $\mathrm{CuO} / \mathrm{Al}_{2} \mathrm{O}_{3} /$ $\mathrm{FeAlO} / \mathrm{FeAl}$ before (1) and after (2) the testing.

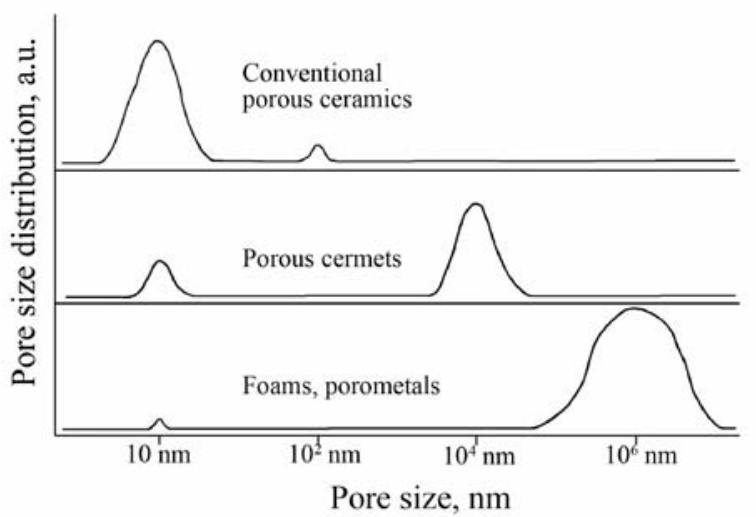

Figure 7. A typical qualitative shape of the pore size distribution for some types of porous materials in comparison with porous cermets. 
component supported by impregnation. Hence, cermet catalyst is comprised of the ceramic matrix on the base of uniformly distributed aluminium and iron oxides with incorporated metal particles.

\subsection{Catalytic brown coal combustion}

Figure 8 shows the brown coal organic matter burn- off during testing. It demonstrates good and stable activity for at least 100 hours time-on-run. The coal organic matter conversion in the presence of cermet catalyst remains in the range of $97.8-98.5 \%$, while without a catalyst it is obviously lower (91.2-94.6\%). The difference is not large, but it should be mentioned that "A gain of even $0.5-1.0 \%$ in the combustion efficiency can save a large amount of money in terms of operating cost of the boiler..." [20].

It is known that oxidation of carbon and organic fraction containing particulates occurs more efficiently on bulk oxides first formed as powders followed by washcoating on supports than on particles of supported oxides obtained by wet impregnation of some supports [6]. In our case one can assume that, along with $\mathrm{CuO}$, FeAlO mixed oxide in cermet is also involved in oxidation of particulates or products of their pyrolysis. The uniform distribution of this component as revealed by the elemental mapping allows to explain a retention of catalyst activity in particulates oxidation even after partial attrition of the catalyst.

Table 1 demonstrates emission of pollutants with the flue gas during catalytic combustion. One can conclude that up to 50 hours of time-on-stream, CO content is increased while that of $\mathrm{NO}_{x}$ goes through the minimum with subsequent stabilization. A moderate variation of catalytic activity in $\mathrm{CO}$ oxidation and $\mathrm{NO}_{x}$ reduction can be controlled both by variation of the oxygen content in catalyst as well as accumulation of sulfites/sulfates (vide infra), thus affecting activity in $\mathrm{NO}_{x}$ reduction by $\mathrm{CO}(\mathrm{CO}+$ $\mathrm{NO}=0.5 \mathrm{~N}_{2}+\mathrm{CO}_{2}$ ) and/or selective reduction by hydrocarbons (products of coal pyrolysis) in the excess of oxygen. Sulphur oxides are probably also bound with ash. Without a catalyst, the concentration of pollutants is substantially higher (Table 1).
Comparison of these data with results of coal combustion in the fluidized bed of the spherical CuCrAIO catalyst demonstrates close combustion characteristics for both catalysts. Thus, for coal combustion in the fluidized bed of CuCrAlO catalyst at 1013-1023 K, concentration of CO was 432 ppm, NO - 458 ppm, $\mathrm{NO}_{2}-45 \mathrm{ppm}, \mathrm{SO}_{2}-0 \mathrm{ppm}$, and the solid fuel burn- off was $98.2 \%$. Hence, fixed bed of the honeycomb cermet catalyst in the fluidized bed of sand provides required characteristics of the combustion process, $\mathrm{NO}_{x}$ reduction being more efficient than in the case of spherical catalyst.

A question of the long-term stability of catalyst in real operation conditions is extremely important. The catalyst of fuels combustion must operate without reloading at least one halfyear season ( $4300 \mathrm{~h})$. Results of this research demonstrated that performance stability of cermet catalyst greatly exceeds that of earlier used catalysts of diesel fuels combustion in catalytic heat generators (CHG) (Table 2).

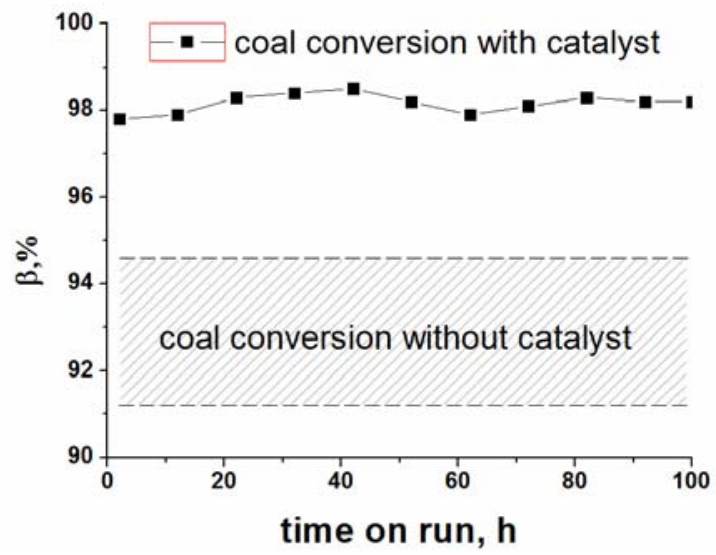

Figure 8. Burn-off of the coal organic matter with the time-on-stream over the cermet catalyst in comparison with the average conversion without catalyst.

Table 1. The content of toxic compounds in the flue gas at $1023 \mathrm{~K}$ with and without catalyst for the brown Kansk-Achinsk coal combustion.

\begin{tabular}{|c|c|c|c|c|c|}
\hline Time-on-stream, $\mathrm{h}$ & $\mathrm{CO}_{2}, \mathrm{vol} \%$ & $\mathrm{CO}, \mathrm{ppm}$ & $\mathrm{NO}, \mathrm{ppm} \quad \mathrm{NO}_{2}, \mathrm{ppm}$ & $\mathrm{SO}_{2}, \mathrm{ppm}$ \\
\hline \hline 2 & 7.41 & 395 & 384 & 36 & 0 \\
\hline 12 & 7.52 & 364 & 376 & 34 & 0 \\
\hline 22 & 7.37 & 399 & 312 & 34 & 0 \\
\hline 32 & 7.40 & 394 & 304 & 34 & 0 \\
\hline 42 & 7.31 & 410 & 312 & 34 & 0 \\
\hline 52 & 7.42 & 430 & 318 & 30 & 6 \\
\hline 62 & 7.48 & 455 & 321 & 23 & 7 \\
\hline 72 & 7.46 & 460 & 323 & 25 & 10 \\
\hline 82 & 7.39 & 479 & 336 & 24 & 8 \\
\hline 92 & 7.47 & 441 & 325 & 25 & 23 \\
\hline
\end{tabular}


Certainly, the intensity of the reaction media effect on catalyst could be substantially higher in the case of diesel fuel combustion as compared with brown coal. However, even for shorter time-on-stream, pronounced decline of traditional supported catalysts activity was observed (Table 2). For $\mathrm{CuCr}_{2} \mathrm{O}_{4}(20 \%) / \mathrm{Al}_{2} \mathrm{O}_{3}$ catalyst the rate of $\mathrm{CO}$ oxidation after operation in $\mathrm{CHG}$ decreased from $\sim 8 \times 10^{15}$ to $2-3 \times 10^{15}$ molecules $/ \mathrm{m}^{2} \mathrm{~s}$ [15]. In all these cases, variation of conversions of butane and $\mathrm{CO}$ due to deactivation was also pronounced. Similar effects are expected for conversions of other fuels due to usually observed correlations in deep oxidation of various compounds [23]. Since in the case of monolithic cermet catalyst variation of both brown coal conversion and residual CO concentration with time-on-stream was very small (vide supra), operational stability of this catalyst appears to be much higher than that of earlier developed catalysts.

In addition, the effect of the coal combustion temperature on the concentration of toxic compounds in the flue gas was studied. Analysis of the flue gas composition was carried after 70 hours of the catalytic package operating (Table 3). As follows from the obtained data, decrease of the process temperature increases $\mathrm{CO}$ concentration and decreases that of $\mathrm{NO}_{x}$. The tendency of the $\mathrm{NO}_{\mathrm{x}}$ concentration to increase with temperature is well known for the gas fuel combustion being caused by the formation of so called "thermal" nitrogen oxides [24]. In our case the same tendency could be explained by decreasing the efficiency of $\mathrm{NO}_{x}$ selective reduction by hydrocarbons on catalysts containing $\mathrm{Cu}$ and $\mathrm{Fe}$ oxides at temperatures above $673 \mathrm{~K}$ [25-27]. In any case, fuel catalytic combustion clearly works well in a broad range of temperatures.

So, catalytic combustion of the brown coal provides better ecological and technical characteristics of the process than combustion without a catalyst. The application of catalysts apparently allows to decrease the temperature of the coal combustion.

\subsection{Catalyst characteristics after testing}

According to XRD data, new phases were not detected in spent catalyst. The relative content of $\mathrm{Fe}_{2} \mathrm{O}_{3}$ was increased after testing probably, due to partial oxidation of metallic particles. Though the content of $\gamma$ - and $\delta-\mathrm{Al}_{2} \mathrm{O}_{3}$ could not be reliably estimated from XRD data, the intensity of $\alpha-\mathrm{Al}_{2} \mathrm{O}_{3}$ diffraction peaks is certainly increased (Figure 5), while that of $\mathrm{CuO}$ varies only slightly. Since the testing catalyst temperature $\left(700-750^{\circ} \mathrm{C}\right)$ is significantly lower than the catalyst calcination temperature during synthesis, this suggests a strong effect of the reaction medium on the catalyst.

After testing, SSA of catalyst decreases to $9.7 \mathrm{~m}^{2} / \mathrm{g}$, and the volume of mesopores declines to $0.042 \mathrm{~cm}^{3} / \mathrm{g}$. The pore size distribution changes as well. Mesopores with the narrow size distribution (maxima $\sim 3 \mathrm{~nm}$ and $\sim 10 \mathrm{~nm}$ ) disappear altogether, while pores with a broad size distribution centered at ca.13 nm are formed, perhaps, due to some changes in the phase composition of alumina globules. The total volume of pores, including mesopores and ultramesopores, remains unchanged. It should be stressed that the catalyst passed

Table 2. Deactivation of $\mathrm{CuCr}_{2} \mathrm{O}_{4} / \mathrm{Al}_{2} \mathrm{O}_{3}$ catalyst after testing in diesel fuel combustion.

\begin{tabular}{|c|c|c|c|}
\hline Catalyst & Time-on-stream, $\mathbf{h}$ & Activity $\mathbf{1 0}^{-2}, \mathrm{~cm}^{3}$ butane/g×s & Ref. \\
\hline \hline $\mathrm{CuCr}_{2} \mathrm{O}_{4}(5 \%) / \mathrm{Al}_{2} \mathrm{O}_{3}$ & 0 & 4.67 & {$[21]$} \\
\hline & 2 & 0.25 & \\
\hline & 43 & 0.14 & \\
\hline $\mathrm{CuCr}_{2} \mathrm{O}_{4}(30 \%) / \mathrm{Al}_{2} \mathrm{O}_{3}$ & 0 & 3.62 & {$[22]$} \\
\hline & 8 & 0.25 & \\
\hline
\end{tabular}

Table 3. Effect of temperature on the $\mathrm{CO}, \mathrm{NO}_{x}, \mathrm{SO}_{2}$ concentration in the flue gas of brown coal combustion in the fluidized bed of sand with the cermet catalyst package,

\begin{tabular}{|c|c|c|c|c|}
\hline T, $\mathrm{K}^{\star}$ & $\mathrm{CO}, \mathrm{ppm}$ & $\mathrm{NO}, \mathrm{ppm}$ & $\mathrm{NO}_{2}, \mathrm{ppm}$ & $\mathrm{SO}_{2}, \mathrm{ppm}$ \\
\hline \hline 1023 & 460 & 321 & 23 & 7 \\
\hline 1013 & 478 & 298 & 19 & 0 \\
\hline 1003 & 505 & 271 & 18 & 0 \\
\hline 993 & 516 & 284 & 18 & 0 \\
\hline 983 & 582 & 274 & 17 & 0 \\
\hline 973 & 669 & 277 & 17 & 0 \\
\hline
\end{tabular}

*Time-on-stream for each temperature about 1 hour. 
through more than ten start-up/shut down procedures of the test installation providing an enhanced duty cycle as compared to 100 hours operation in the usual steady state mode.

Analysis of sulphur content in the tested catalyst by EDX revealed that sulfur content in the bulk is about $0.2 \mathrm{wt} . \%$, while on the surface of honeycomb wall (depth $\sim$ few microns) its average concentration is $\sim 6.6 \mathrm{wt} . \%$. Sulfates could be mainly bound with amorphous alumina inclusions. Accumulation of sulfur compounds in the surface layer explains retention of high activity in $\mathrm{CO}$ oxidation and $\mathrm{NO}_{\mathrm{x}}$ reduction occurring in the bulk of porous cermet even after testing for $100 \mathrm{~h}$.

Special tests have not revealed any detectable loss of weight after the run in the catalytic reaction thus demonstrating a good attrition resistance of cermet catalyst in the fluidized bed of sand and coal particulates. Small (if any) weight loss due to attrition could be masked by the weight gain due to sulfur absorption and partial oxidation of metal particles.

\section{References}

[1] L.Pfefferle, W.Pfefferle, Catalysis in combustion, Catal.Rev. Sci.Eng., 29 (1987) 219-267.

[2] R.M.Heck, R.J.Farrauto, Catalytic air pollution control. Commercial technology, Van Nistrand Reinhold, New York, 1995.

[3] D.Klvana, J.Kirchnerova, J.Chaouki, J.Delval, W.Yaïci, Fibersupported perovskites for catalytic combustion of natural gas, Catal.Today, 47 (1999) 115-119.

[4] C.Lahousse, A.Bernier, P.Grange, B.Delmon, P.Papaefthimiou, T.loannides, X.Verykios, Evaluation of $\gamma$-MnO2 as a VOC removal catalyst: comparison with a noble metal catalyst, J.Catal., 178 (1998) 214-225.

[5] S.R.Vailant, A.S.Gastec, Catalytic combustion in a domestic natural gas burner, Catal.Today, 47 (1999) 415-420.

[6] R.J.Farrauto, K.E.Voss., Monolithic diesel oxidation catalyst, Appl.Catal. B: Environ., 10 (1996) 29-52.

[7] A.D.Simonov, N.A.Yazykov, V.N.Parmon., A New Approach to Organize the Catalytic Reactions. Book of Abstracts 4th European Congress on Catalysis, 1999, Rimini, Italy, p. 521.

[8] N.A.Yazykov, A.D.Simonov, T.I. Mishenko, A.S. Aflyatunov, S.V. Smolin, V.N.Parmon, Fuel combustion in the fluidized bed of an inert material with an unmovable catalytic smallvolume package, Khimiya v Interesakh Ustoichivogo Razvitiya (Chemistry for Sustainable Development) 1 (2003) 321-326.

[9] A.Kaddouri, N.Dupont, P.Gélin, P.Delichére, Methane Combustion Over Copper Chromites Catalysts Prepared by the Sol-Gel Process, Catal.Lett. 141 (2011) 158-162.

[10] J.W.Geus, J.C. van Giezen, Monoliths in catalytic oxidation, Catal.Today, 47 (1999) 169-180.

[11] Zolotovskii, B.P, Buyanov R.A., Buhtiyarova G.A., Taraban T.A., Murin V.I., Grunvald V.R., Demin V.Z., Sayfullin R.A., Development of the technology and production of spherical alumina for catalysts supports and adsorbents, Russian Journal of Applied Chemistry, 70 (1997) 285-291.

\section{Conclusions}

Pilot tests of the brown coal combustion over porous honeycomb cermet catalyst fixed in the fluidized bed of sand have been carried out. A higher coal burn off as well as a lower emission of gas contaminants compared to non-catalytic combustion is demonstrated. Some processes of the catalysts ageing during its operation have been studied and discussed. The catalyst reveals a good attrition resistance making it promising for the oxidation of other solid particulate fuels like lignite and peat as well as wastes.

\section{Acknowledgements}

This work was supported in part by Grant of RFBR No 11-0800704 and by Federal Targeted Program "R\&D in Priority Fields of the Scientific and Technological Complex of Russia" (Contract No 16.515.11.5001.).

[12] S.Tikhov, V. Usoltsev, A. Salanov, S. Tsybulya, Yu. Chesalov, G. Kustova, V. Sadykov, G. Golubkova, O. Lomovskii, Design of composite porous cermets synthesized by hydrothermal treatment of CrAl powder followed by calcination, J. Mater. Sci., 45 (2010) 3160-3168.

[13] J. Goldstein, D. Newbury, D. Joy, C. Lyman, P. Echlin, L. Sawyer, J.M. Michael, Scanning Electron Microscopy in X-Ray Microanalysis, Springer, New York, 2008, pp. 485499.

[14] A.Andreev, A.Salanov, S.Tikhov, S.Cherepanova, V.Zaikovskii, V.Usoltsev, V.Sadykov and O.Lapina, Formation of micro, nano and atomic- level structure of CoAlO/Co-Al cermets prepared by mechanical alloying, J. Mat. Sci. Eng. A, 2 (2012) 121-136.

[15] D.A.Arendarskii, Z.R.Ismagilov, G.B.Barannik., Study of the deactivation and regeneration of copper chromite on $\gamma$-alumina and magnesium chromite on $\gamma$-alumina catalysts for fuel combustion, Catal.Lett., 15 (1992) 347-351.

[16] G.Xantohopoulou, G.Vekinis, Deep oxidation of methane using catalysts and carriers produced by self-propagating high-temperature synthesis, Appl.Catal.A: Gen, 199 (2000) 227-238.

[17] S.F.Tikhov, V.V.Usoltsev, V.A.Sadykov, S.N.Pavlova, O.I.Snegurenko, L.L.Gogin, Z.Yu.Vostrikov, A.N.Salanov, S.V.Tsybulya, G.S.Litvak, G.V.Golubkova, O.I.Lomovskii., CrAl alloy-based monolith with polymodal pore structure for partial oxidation of methane to synthesis-gas, Stud.Surf.Sci. Catal., 162 (2006) 641-648.

[18] S. F. Tikhov, V. B. Fenelonov, V. A. Sadykov, Yu. V. Potapova A.N.Salanov., Porous Al2O3/Al Metal Ceramics Prepared by the Oxidation of Aluminum Powder under Hydrothermal Conditions Followed by Thermal Dehydration: I. Composition and Macrocharacteristics of Composites, Kinet.Catal., 41 (2000) 826-834. 
[19] A.N.Leonov, O.L.Smorygo, A.N.Romashko, M.M.Dechko, A.A.Ketov, L.A.Novikov, V.V.Tankovitch, Comparative estimation of properties of monolith supports with honeycomb and cellular structures from the viewpoint of their use in catalytic purification of gases, Kinet. Catal., 39 (1998) 634-644.

[20] P.Basu., Combustion and gasification in fluidized beds, CRC Tailor \&Francis Group, Boca Raton, Florida, 2006.

[21] D.A.Arendarskii, E.A.Paukshtis, Z.R.Ismagilov, E.N.Yurchenko, Optical spectroscopic studies of CuCr2O4/ $\gamma$-Al2O3. Catalyst deactivation under operation in catalytic heat generators, React.Kinet.Catal.Lett, 28 (1985) 195-201.

[22] D.A.Arendarskii, A.V.Pashis, A.P.Shepelin, Z.R.Ismagilov, XPS studies of Cu-Cr catalyst deactivation in catalytic heat generators , React.Kinet.Catal.Lett, 28 (1985) 211-217.

[23] G.K. Boreskov, in: J.R. Anderson, M. Boudart (Eds.), Science and Technology, vol. 3, Springer Verlag, Berlin-HeidelbergNewYork, 1982, p. 39.
[24] S.Etemad, H.Karim, L.L.Smith, W.C.Pfefferle., Advanced technology catalytic combustor for high temperature ground power gas turbine application, Catal.Today, 47 (1999) 305314.

[25] A.Obuchi, I.Kaneko, J.Oi, O.Akihito, A.Ogata, G.R.Bamwenda, S.Kushiyama., A practical scale evaluation of catalysts for selective reduction of NOx with organic substances using a diesel exhaust, Appl.Catal.B: Environ. 15 (1998) 37-44.

[26] C.Torre-Abreu, C.Henriques, F.R.Ribeiro, G.Delahay, M.F.Ribeiro, Selective catalytic reduction of NO on copperexchanged zeolites: the role of the structure of the zeolite in the nature of copper-active sites, Catal.Today, 54 (1999) 407-418.

[27] H.-Y.Chen, T.Voskoboinikov, W.M.H.Sachtler, Reduction of NOx over Fe/ZSM- 5 catalysts: mechanistic causes of activity differences between alkanes, Catal.Today, 54 (1999) 483494. 